\title{
Study on Irrational Strategic Management
}

\author{
Yongbo Guo \\ College of Industrial and Commercial Administration, Tianjin Polytechnic University \\ Tianjin 300387, China \\ E-mail: guozhang_44@163.com
}

\begin{abstract}
With the development of economy, original pure rational strategic management could not adapt to the complex and ever-changing environment now. A kind of irrational strategic management is emerging quietly. This passage introduces the development of irrational strategic management and its function in strategic management, and discusses the way of irrational factor playing an active role in strategic management.
\end{abstract}

Keywords: Strategic management, Rational management, Irrational factor

\section{Rational strategic management and its predicament}

Rationality has a deep-rooted tradition in enterprise management. From Adam Smith, economics saw people as rational animal. The appearance of the rational people influenced the subsequent management even more deeply. The strategic management has showed itself in the rational way from its forming. From the design and plan school in the 60s to the dominant position of location school in the $80 \mathrm{~s}$, until the rising of core school in the $90 \mathrm{~s}$, all emphasized the rational character of strategic management [1]. The thought of rational strategic management supposes the environment of the enterprise facing is simple, small changes and expectant, so, the enterprise can be expectant for the market and the future. But today, the environment of the enterprise facing is not only complex, but also less and less expectant. If the enterprise emphasizes the rational way, it may concern with management efficiency and stylization of forming strategic management excessively, which will create a kind of inertia of strategic management. After the 1970s, the operation and management of Japanese enterprises shocked the United States. Compare with the management differences of the United States and Japanese, we can find that the United States frustrated in the competition of operation and management with Japanese, which showed the predicament of rationalism in modern enterprise management.

\section{The irrational strategic management and its rising}

People often see the irrational factor as the opposition of rationality, and think it is not rational, loss of rationality, and negative rationality. In fact, irrationality means the spirit property of no conscious, tuition, emotion and belief which not belongs to the rational factor and corresponding with rationality, it is a natural part of human nature.

Irrational strategic management means that in the complex strategic management activity, the manager except playing the role of rational strategic management through necessary data analysis, predict and logical reasoning, should change the concept of efficiency supremacy, and should be people-centered, take sentiment as main line, pay attention to play the role of irrational factors, such as faith, sentiment, will, mind-set, intuition and so on, which can be used to excavate staff's potential and enthusiasm, attract consumer's attention and support, create the environment of the three (manager, staff and consumer) common recognition, form the group's values and cohesion, and achieve the harmonious management of the aim of strategic management. The core of irrational strategic management is people-centered, attach importance to people's emotional factors, respect people, depend on people and develop people.

In 1924, the results of Hawthorne experiment carried out by Mayo shows that people is not only economic people, but also the society people who have irrational factors, such as desire, demand, emotion and so on. Members who have common feeling, attitude and value in the work constitute the informal organization, which influences members' action with stable authority form and irrational emotional logic [2]. Now, the birth of the theory of knowledge management, building a learning organization promotes the symbiotic integration of rational and irrational management. On the one hand, it promotes rationality as the role of achieving irrational tool by making full use of scientific method and means which can make knowledge doing identification, processing and dissemination. On the other hand, it pays attention to playing the role of irrational factors, such as people's desire, emotion, interests, will and so on in management, encourages innovation, promotes learning and exchanges, enhances the ability of facing changes, and makes the irrational factors in the framework of rationality play the active role of cohering popular feeling, management innovation under the guidance of scientific way. 


\section{The function of irrational factors in strategic management}

Irrational factor, as a kind of spirit composition and existence way, mainly concludes the needs, emotion, feeling, will, faith, belief, unconsciousness, intuition, inspiration and so on. Irrational factors play an important way in the whole process of strategic management, mainly in the following aspects:

\subsection{Irrational factors guide the strategy manager to get information}

Essentially, strategic management is a manager's idea of future development of the enterprise, which has uncertainty character. What the information the manager faces before he making decision is complex and difficult to get by data analysis and logical reasoning. The most important information for strategic planning may beside the manager's hand, or may lose evanescently. It needs manager to find and grasp information by rich experience and exceptional insight. The three-year-old daughter of Lande, the leader of Polaroid asked him, why she could not see her photos at once. Less than one hour, this scientist formed a strategic thought of image camera, which took a turn for the better for his company. From this example we can see that this strategic thought comes from the sudden comprehension for his daughter's question and his broad technical knowledge.

\subsection{Irrational factors support strategy manager to carry out information analysis}

When a new environment comes quietly, or an enterprise faces crisis or the strategy turning point, people cannot make data analysis at this time, and cannot forecast the future. To be brief, rational analysis mode cannot provide an accurate answer at this time. People must analyze and make decision by their own intuition and sense and insight under situation of uncompleted information, unsure circumstance and unclear state. Irrational strategic mode may be the only choice at this time. It is the manifestation of the two situations that the strategies choose of the company of Intel from the number one company of memory production to microprocessor market. In accordance with traditional analysis, this decision is simply inconceivable, unconscionable. At that time, memory service is the company's absolutely leading service, and the sales volume of microprocessor is small among the 2000 kinds of products. For this, the former president of Intel Andy Grove has a wonderful experience summary, "Sometimes, the experience tells you that some factor is very weak now, and is insignificant in data analysis, but it has great development potential, and you will change your management rule in the future. In other words, in the process of treating the impact of budding trend, you should go out of the rigid data analysis, and depend more on perception and knowledge to decide."

\subsection{Irrational factors help improve the efficiency and quality of decision making}

Decision makers do not only depend on rational judgment when they choose programs among lots of options. Simon affirmed that it was exist intuitive thinking during the process of program design and selection. He thought that intuition is a kind of thinking pattern. Depending on intuitive thinking can breakthrough the restrictions of logical thinking on the basis of logical thinking results in the past, and can save time of reasoning [3]. In the practice of strategy decision making, people who doing the choice of decision making program by using intuition are mainly experienced experts and senior managers in the organization. They do not do it by using logical thinking, but making decision as soon as possible under the analysis of intuitive thinking and some rational analysis. When the company of Volvo in Sweden sold their cars to American market, all the analysis get the result that Volvo has no competition and it cannot succeed in American market. But Benguela insisted on his own intuitive judgment, he thought that the car will surely succeed in the largest market in the world through all kinds of methods. The result proves his intuitive judgment. Just as the former CEO of this company said, "intuitive feeling really significantly impact on strategic actions, though strategic decision, such as large scale investment will be naturally influenced by economic analysis and forecast, strategy is dominated by feeling and intuition to a certain extent, because the future profit is difficult to estimate. This is a complex thing, and you cannot forecast forever, must be feeling right."

\subsection{Irrational factors promote the smooth implementation of strategic decision}

Good strategic decision needs executor to implement. If strategy has not been smoothly implemented, it will fail in the end. Therefore, the coordination and communication between decision maker and executor are very important. The essence of communication is emotional communication. Emotion promotes effective interaction between manager and executor. Emotion, as an irrational factor, can promote all staff's ambition and struggling spirit, and stimulate activity through conveying goal to the staff to make them has an identical direction [4]. For example, the Japanese leaders pay attention to the role of emotional factor in strategic management. Komatsu proposes the slogan of "surround Caterpillar". Canon Corporation wants "to attack Xerox Corporation", Honda Corporation takes "to try its best to become the automobile industry pioneer like Ford" as the power of going forward. They will stimulate staff's enthusiasm through slogan or strategic intention, and achieve the company's final goal at last. Concerning the unique role of emotion in the process of strategic management, Phillips, the famous learner, summarized exactly, he said, "strategy has no value in itself, and it only has significance for people who participate enthusiastically." From this aspect, good strategy is to stimulate staff's participation enthusiasm. Strategy can play its role if staff has enthusiasm. 


\subsection{The negative role of irrational factors in strategic management}

Irrational factor is a double-edged sword. Due to the non-logical and non-critical features of irrational factors, they inevitably have negative role which can not be neglected in management activity. Irrational factors easily lead to misleading information and decision errors. During the process of information collection, one-sidedness of irrational factors may limit the scope of attention. The desire of diversity will not make attention focus on a particular goal. The speed and accuracy of information gathering and processing will be affected if the emotion and feeling are more than or less than a certain level of intensity. Irrational factors, such as intuition and inspiration, are short of rigidity and reliability, or even are illusion. Abusing them will lead to major mistakes in decision making. Negative emotion will also make leaders become inconstancy, bring hindrance for the communication, and lower management efficiency and the effectiveness of organization activity and individual action, and effect the achieving of organization goal at last.

\section{The way of leading irrational factors to play its active role in strategic management}

\subsection{Paying attention to and cultivating irrational factors, promoting rationality and irrationality harmonious} development

The aim of learning and thought of strategic manager is not only mastering methods and rules, being able to use conventional methods of strategic management to making strategic analysis and decision, but also stimulating thought, improving creativity and innovational ability. During the management training, managers should pay attention to emotional shape, will training and correct beliefs establishing to improve managers' EQ and accumulate management experience. During learning knowledge, people should pay attention to improve intuition ability, and exert the creativity of intuition and inspiration through continuous accumulation. On weekdays self-shaping, people should strengthen the critical self-awareness, and debug and change character and action by using the power of will, and persistently carry out self-examination and self-encouragement. So that they can exceed the knowledge constrains, gain wisdom enlightenment, which can promote the harmonious development of emotion and reason under the guide of sense.

\subsection{Perfect the people-management, play the core role of people in management}

The people-management, centered on people, is on the basis of scientific management theory and method to make strategic management process, method and system correspond with human nature, and focuses on people's inner world, bases on the real need of people and guided by emotion, exerts human nature, excavates people's potential, mobilizes people's enthusiasm and creativity to increase members' happiness, makes everyone get oneself development and satisfaction through serving for organization, and achieve the aim of harmonious development between organization and people. Strategic managers not only need respect people, but also exert people's ability and value, meet the needs of human nature, treat employees correctly, set the concept of unity among manager, employee and enterprise, increase employees' belongingness. Giving up the pursuit of efficiency, people should pay attention to the embodiment of personal value in the work, and promote the smooth achieving of strategic aim through achieving personal value.

\subsection{Strengthen the emotional management and promote effective management communication}

When the manager formulate and implement strategic planning, they should pay attention to the role of management communication, and strengthen emotional investment, create a relax and warm working environment, cultivate close relationship, strengthen positive incentives, pay attention to two-way communication and exchange, attract, retain and cultivate talents to make employees get self-esteem satisfaction, and reduce frustration, increase enthusiasm, inspire initiative and creativity, enhance the cohesion of the organization, meet the employees' needs of high-level demand, to truly achieve the management of fitting human nature. Through the emotional communication in the process of strategic implementation, the organization's mission, desire and ideas will form members' thought pattern and behavior through a variety of effective communication channels. They cultivate employees the common belief. Finally, it internalizes organizational culture.

\subsection{Establish a sound management system and norms, weaken the negative role of irrational factors}

In the process of strategic management, we emphasize the management of human nature, people-management, self-discipline of the people, at the same time, we also clearly recognize the irreplaceable role of laws and norms. A comprehensive and rational management operational mechanism and perfect management behavioral assessment system and monitoring system will help establish the concept of contract, the sense of equality, and can strengthen action constraint, improve management efficiency, thus, it can curb unreasonable needs, reduce the negative impact brought by irrational factors, such as blindly emotional and conscious impulse, and intuitive mistakes.

\section{Conclusions}

This passage studies on the role of irrational factors in the process of strategic management, and attempts to change the situation of neglecting irrational problem in strategic management in the past. The aim of this passage is not exaggerating irrational factors in order to play down the rational factors, but is hoping to envisage the important role of irrational factors in strategic management activity, probing that how to exert the active role of irrational factors under 
the guidance of rationality, weakening the way of its negative role, serving strategic decision making, and achieving the goal of sustainable development and harmonious social development.

\section{References}

Liu, Huawen \& Tan, Liwen. (2008). New Trend of Overseas Strategy Management Study. Science \& Technology Progress and Policy, January, 191-195.

Qi, Xuerui. (2000). Scientific decision-making and irrational factors research. Master's Degree Thesis, Guangxi Normal University, 143-147.

Stephen Robins. (2004). Management. Beijing: China Renmin University Press, (Chapter5).

Zhang, Xiaoyi. (2007). The role of irrational factors play in management. Master's Degree Thesis, Heilongjiang University, 93-96.

Zhao, Xianjin. (2008). The emerging of irrational pattern of enterprise' strategic management. Scientific Management Research, April, 109-110. 